\title{
Ten years after Dublin: principal trends in HIV surveillance in the EU/EEA, 2004 to 2013
}

A Pharris (anastasia.pharris@ecdc.europa.eu)1 ${ }^{1}$, G Spiteri' ${ }^{1}$, T Noori ${ }^{1}$, A J Amato-Gauci

1. European Centre for Disease Prevention and Control (ECDC), Stockholm, Sweden

Citation style for this article:

Pharris A, Spiteri G, Noori T, Amato-Gauci AJ. Ten years after Dublin: principal trends in HIV surveillance in the EU/EEA, 2004 to 2013. Euro Surveill.

2014;19(47):pii=20968. Available online: http://www.eurosurveillance.org/ViewArticle.aspx?Articleld=20968

In 2004, the 31 countries of the European Union and European Economic Area (EU/EEA) adopted the Dublin Declaration on Partnership to Fight HIV/AIDS in Europe and Central Asia. In 2013, 29,157 persons were diagnosed with HIV in 30 EU/EEA countries (adjusted rate: $6.2 / 100,000$ ); new diagnoses have increased by $33 \%$ since 2004 among men who have sex with men and late diagnosis remains common. Evidence-based prevention measures and efforts towards earlier testing need to be expanded.

\section{Newly diagnosed HIV infections}

In 2004, countries in Europe and Central Asia adopted the Dublin Declaration on Partnership to Fight HIV/ AIDS, making human immunodeficiency virus (HIV) an important political priority for countries in the European Union and European Economic Area (EU/EEA). Over the last decade, concerted efforts have been made to prevent and control HIV in the region and new effective tools have emerged to reduce HIV transmission [1]. However, since 2004, more than 300,000 people have been newly diagnosed with HIV in the EU/EEA [2] and a considerable proportion remain undiagnosed [3].

Enhanced HIV surveillance for the EU/EEA is coordinated by the European Centre for Disease Prevention and Control in collaboration with the World Health Organization (WHO) Regional Office for Europe. In 2013 , 29,157 persons were diagnosed with HIV in 30 countries of the EU/EEA, a rate of 6.2 per 100,000 population and nearly 32,000 new diagnoses when adjusted for reporting delay $[2,4]$. The majority of those diagnosed were men (male-to-female ratio: 3.2). Transmission was mostly reported as sexual, with 12,228 new diagnoses attributed to sex between men ( $42 \%$ ) and 9,449 to heterosexual sex (32\%). Injecting drug use accounted for 1,455 cases ( $5 \%$ ) and unknown transmission for 5,741 (20\%), while mother-to-child, nosocomial and transfusion-related transmission accounted for less than $1 \%$ of new diagnoses.

Among cases with known information on region of origin or country of birth $(88 \%, n=25,568), 35 \%(n=9,032)$ of people newly diagnosed with HIV in 2013 originated from outside the country in which the diagnosis was made; $15 \%(n=3,784)$ originated from a country with a generalised HIV epidemic.

\section{Trends in newly diagnosed HIV infections}

Overall, HIV diagnosis rates remained largely stable during the studied period, and ranged between 6.5 per 100,000 population in 2004 and 6.2 per 100,000 in 2013 when adjusted for reporting delay. To further understand trends by subgroup, we analysed data from 25 EU/EEA countries, all EU/EEA countries except Bulgaria, Estonia, Italy, Liechtenstein, Poland, and Spain which reported data on HIV transmission, sex and age group for more than $50 \%$ of their cases for the period 2004 to 2013 to The European Surveillance System (TESSy).

Among men, HIV diagnoses increased by $6 \%$ over the analysed period from 14,769 to 15,622 , while HIV diagnoses among women decreased by $40 \%$ from 8,611 to 5,182 (Figure $1 \mathrm{~A}-\mathrm{C}$ ). The increase in diagnoses among men is driven by the $33 \%$ increase among men who have sex with men (MSM) over the last decade, while diagnoses among male heterosexuals from countries with generalised epidemics and other male heterosexuals decreased by $60 \%$ and $19 \%$, respectively (Figure 1B). Male cases attributed to injecting drug use declined by $34 \%$ from 1,273 to 840 , although an increase was noted in 2011 and 2012 following localised outbreaks in Athens and Bucharest [5]. HIV diagnoses among women declined in all transmission categories, with the most notable decreases among heterosexuals from countries with generalised HIV epidemics $(61 \%$, from 4,465 to 1,733 ) and $43 \%$ fewer cases attributed to injecting drug use (from 344 to 197) (Figure $1 \mathrm{C}$ ). These numbers are unadjusted and thus, a small part of the decreases observed may be due to reporting delay. For the same reason, increases observed over the period are likely to be underestimates.

Of all cases in all transmission categories notified between 2004 and 2013, 34\% were aged 30 to 39 years (Figures $2 \mathrm{~A}-\mathrm{C}$ ). The number of diagnoses among MSM increased annually in all age groups, with the largest 
Trends in reported HIV diagnoses, by transmission mode and year of diagnosis, adjusted for reporting delay, EU/EEA, 2004-13
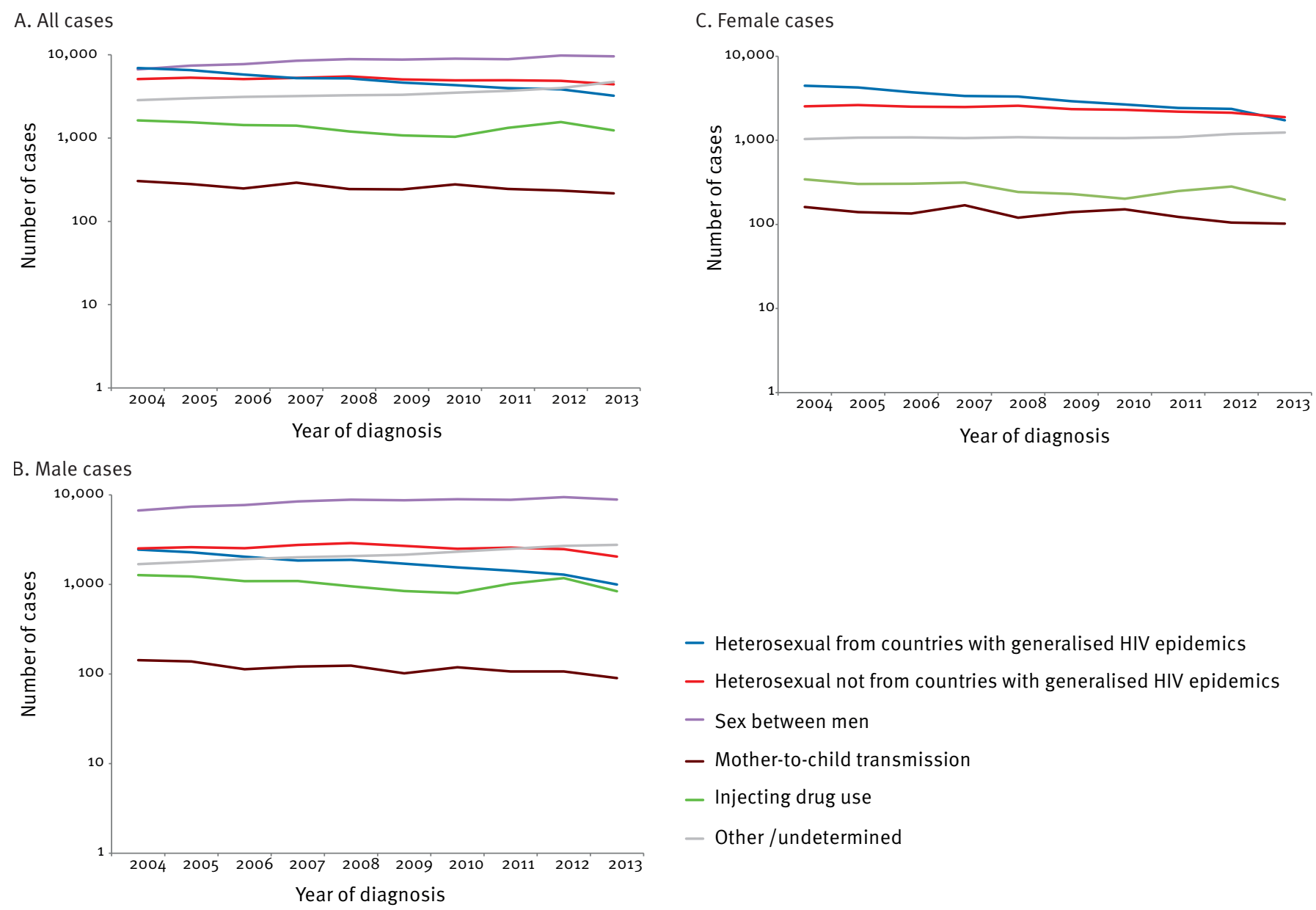

EU/EEA: European Union and European Economic Area; HIV: human immunodeficiency virus.

Case numbers are presented on a logarithmic scale. Excludes data from countries with changed coverage over the period (Bulgaria, Italy, Spain) and incomplete data on transmission mode (Estonia, Poland).

increases among men under 30 years of age, where cases nearly doubled (from 76 to 139 in 15 to 19 yearolds and from 1,585 to 2,728 in 20 to 29 year-olds) and among MSM older than 50 years, where diagnoses increased from 644 to 1,082 (Figure $2 \mathrm{~A}$ ). Among cases attributed to injecting drug use, there were decreases in all age groups except for those older than 50 years where diagnoses increased from 43 to 101 (Figure 2B). Among heterosexuals from countries with generalised HIV epidemics there were decreases in all age groups, most notably among those younger than 30 years where diagnoses declined to one quarter of the number diagnosed in 2004 (from 2,378 to 564) (Figure 2C).

\section{Trends in late diagnosis}

Among 12 EU countries (Austria, Bulgaria, Czech Republic, Cyprus, Denmark, Spain, Luxembourg, Netherlands, Romania, Slovakia, Slovenia, and the United Kingdom) reporting data on $\mathrm{CD}_{4}{ }^{+} \mathrm{T}$-cell count at diagnosis for more than $50 \%$ of their cases for the period 2004 to 2013, the proportion of cases diagnosed late $\left(\mathrm{CD}_{4}{ }^{+}\right.$T-cell count $\measuredangle 350$ cells $\left./ \mathrm{mm}^{3}\right)$ [6] declined, from $55 \%$ of new diagnoses with $\mathrm{CD}_{4}{ }^{+}$data available in 2004 to $44 \%$ in 2013 (Figure 3). During the same period, the median $\mathrm{CD}_{4}^{+}$T-cell count at diagnosis increased from 312 to 390 cells $/ \mathrm{mm}^{3}$. Analysed by transmission group, there was a decline in late diagnosis among MSM (from $43 \%$ to $34 \%$ ) as well as among heterosexuals from countries with generalised epidemics (from $66 \%$ to $60 \%$ ). Late diagnosis among heterosexuals not originating from countries with generalised HIV epidemics was $54 \%$ in 2004 and $53 \%$ in 2013. Late diagnosis attributed to injecting drug use increased slightly, from $50 \%$ to $53 \%$.

\section{Discussion and conclusion}

Although the rates of HIV diagnoses in the EU/EEA have remained largely stable since 2004, the year the Dublin Declaration was adopted, the epidemiology of HIV in the region has changed substantially. New HIV diagnoses among MSM have increased considerably and presently account for more than $40 \%$ of all diagnosed cases in the EU/EEA. The observed increases among younger MSM are of particular concern, as these are likely to 


\section{FIGURE 2}

Trends in reported HIV diagnoses, by age group, year of diagnosis and transmission category, EU/EEA, 2004-13

A. Men who have sex with men

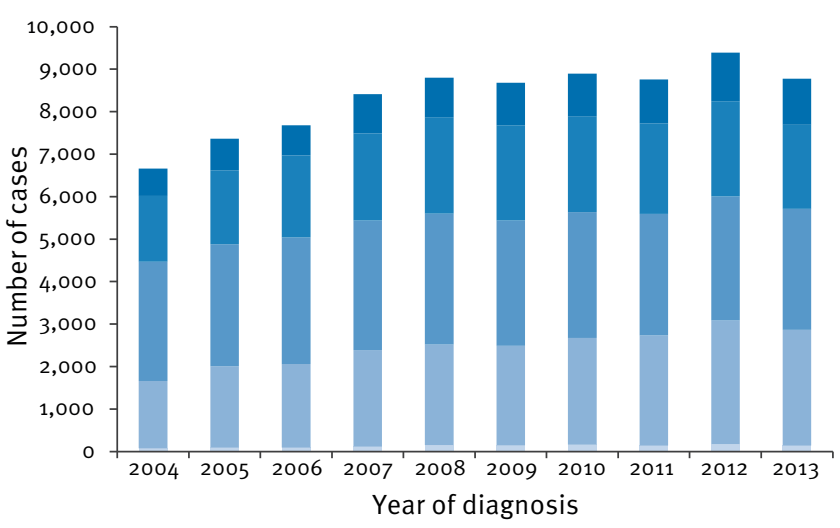

B. People who inject drugs

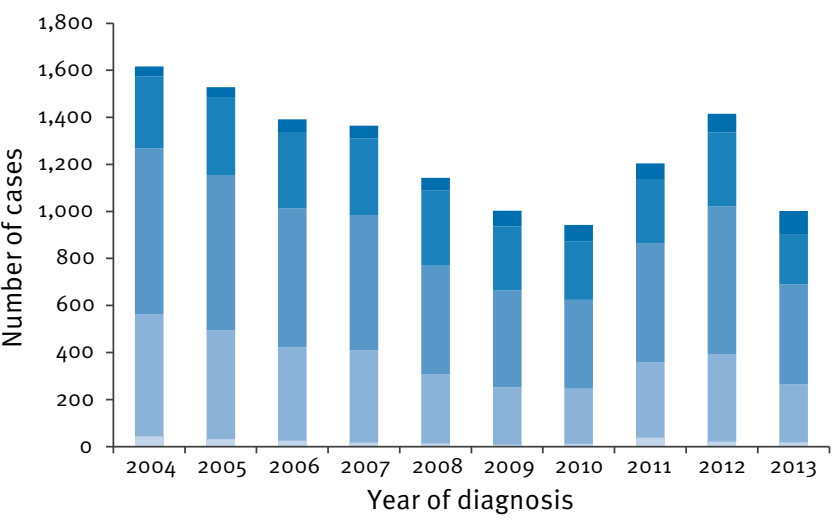

C. Heterosexuals from countries with generalised epidemics

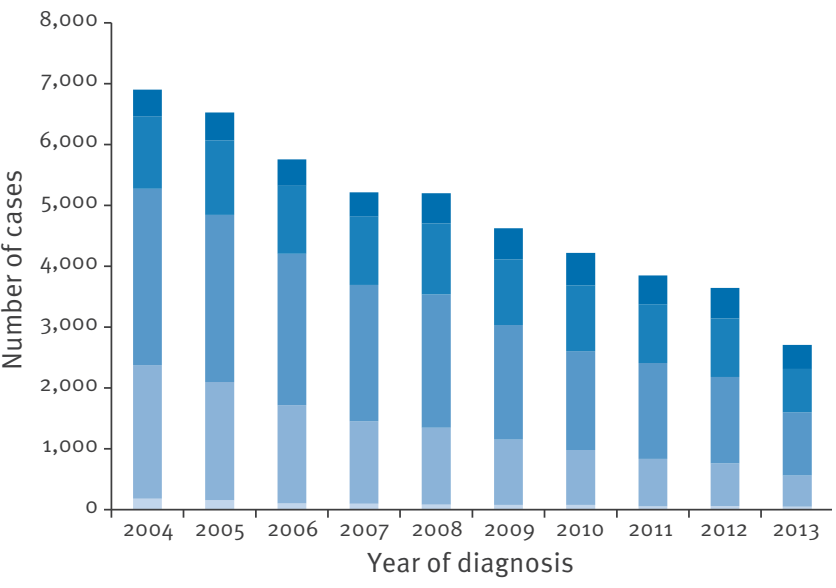

$\geq 50$ years $\quad$ 40-49 years 20-29 years 30-39 years $15-19$ years

EU/EEA: European Union and European Economic Area; HIV: human immunodeficiency virus.

Excludes data from countries with changed coverage over the period (Bulgaria, Italy, Spain) and incomplete data on transmission mode (Estonia, Poland). have been infected more recently and suggest that current prevention efforts may not be having the impact necessary to reduce transmission. Increased HIV incidence and high proportions of undiagnosed infections among MSM have been reported in various settings in the EU/EEA [7-9] and to counter this, evidence-based, comprehensive prevention and testing programmes must urgently be scaled up in many EU/EEA countries.

Our analysis indicates that $35 \%$ of new HIV diagnoses in Europe occurred in people born outside of the country in which the diagnosis was made. Although HIV diagnoses among migrants from countries with generalised HIV epidemics have decreased significantly over the last decade, they still constitute $15 \%$ of all HIV diagnoses in the region. Prevention programmes targeting migrants have not increased in most EU/EEA countries during the period [10], however, the observed decline may partially reflect the documented declining incidence of HIV in many countries with generalised HIV epidemics [11], changes in migration flows to and/ or from EU/EEA countries or a combination of these and other factors. Considering that post-migration HIV acquisition can account for a significant proportion of infections, it is becoming more and more crucial that HIV prevention and testing are promoted and delivered in a manner that is acceptable to migrant populations, along with policies to ensure linkage and access to HIV care $[12,13]$.

Late HIV diagnosis is a critical public health challenge in EU/EEA countries. Late diagnosis is associated with nearly 10 -fold higher mortality in the year following diagnosis, higher morbidity and healthcare costs, and increased duration of possible HIV transmission before being diagnosed and treated [14-16]. While HIV surveillance data indicate that that the proportion of people diagnosed late has decreased slightly over the last decade, late diagnosis remains prevalent in all subgroups and constitutes a major obstacle to the success of HIV prevention and control in the EU/ EEA. Some subgroups, such as people from countries with generalised HIV epidemics and people who inject drugs, were persistently diagnosed later than others, potentially indicating poorer access to HIV testing and inadequate linkage to care [17]. Scaled-up and innovative approaches to routine HIV testing offered in community and clinical settings, including indicator-guided testing can help reach people that are at higher risk and reduce rates of late diagnosis in Europe [18].

There are several limitations to this analysis. Firstly, data quality for some variables (transmission mode, $\mathrm{CD}_{4}{ }^{+} \mathrm{T}$-cell count) was low or changed over the period for some countries. This was addressed by limiting the analysis to countries with more than 50\% completeness on these variables for all years during the period. Secondly, data on transmission mode in particular, contained a significant proportion of unknowns (overall ca $20 \%$ in 2013); for MSM in particular, numbers are likely to be underestimated. Finally, surveillance 
Proportion of new HIV diagnoses with CD4+ T-cell count $<350 / \mathrm{mm}^{3}$ and $<200 / \mathrm{mm}^{3}$ and median CD4+ T-cell count at diagnosis, 12 EU/EEA countries, 2004-13 $(\mathrm{n}=112,764)$

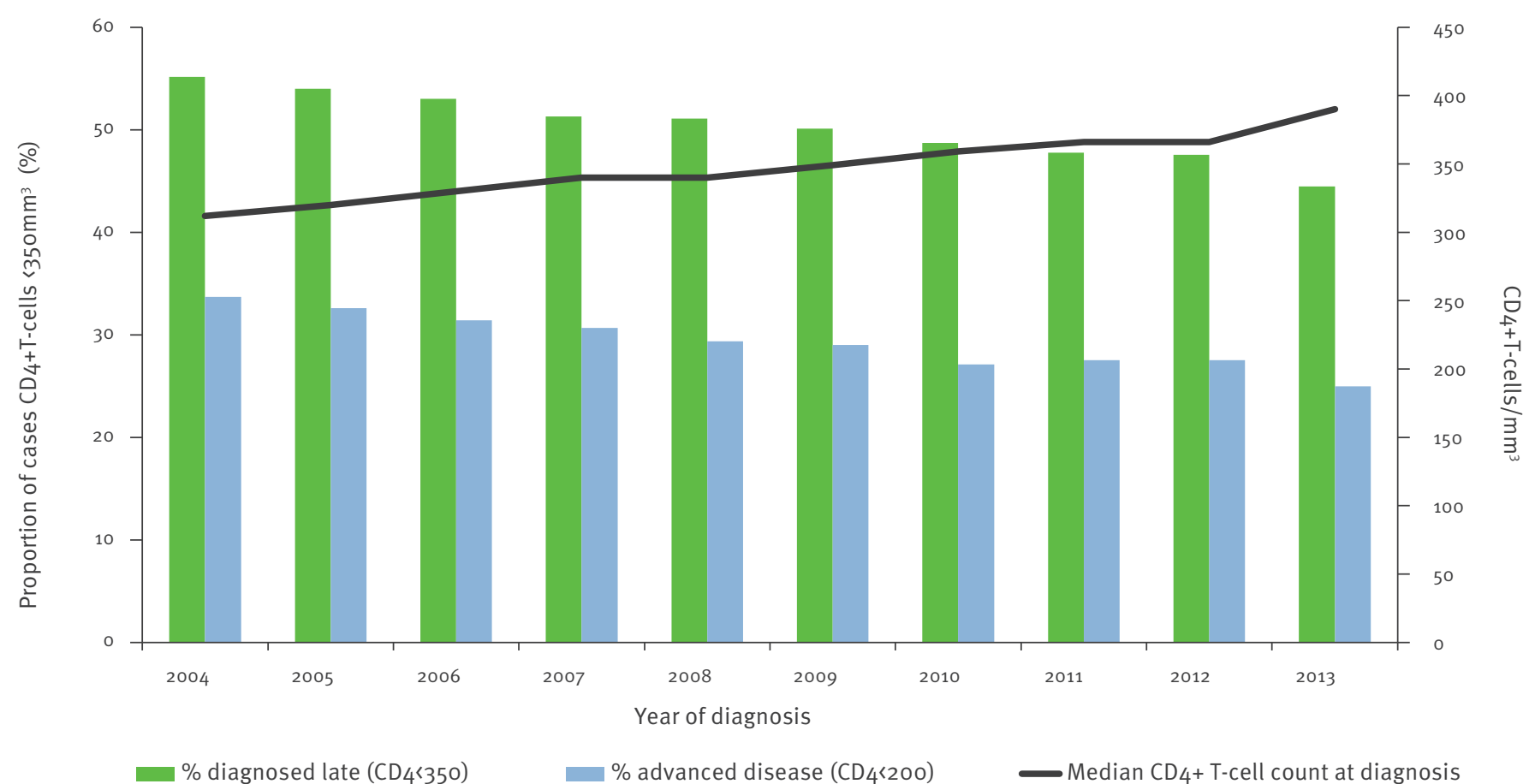

EU/EEA: European Union and European Economic Area; HIV: human immunodeficiency virus.

Countries included: Austria, Bulgaria, Czech Republic, Cyprus, Denmark, Spain, Luxembourg, the Netherlands, Romania, Slovakia, Slovenia and the United Kingdom.

data are subject to reporting delay, and this was only partially taken into account in the analyses presented here. This could mean that reported decreases are likely to be overestimated while reported increases are likely to be underestimates.

Over the past decade, HIV has been high on the political agenda in the EU/EEA. This is reflected in a number of high-level events hosted by the European Council and the adoption of two EU Commission Communications and Action Plans on HIV/AIDS $[19,20]$. In November 2014, the Italian Presidency of the Council of the European Union will host a ministerial conference in Rome to reflect on achievements made since the adoption of the Dublin Declaration in 2004 and to focus attention on aspects of the response that need to be strengthened. Based on an analysis of the epidemiology of HIV in the EU/EEA, in order to have a measureable impact on reducing the HIV epidemic in EU/EEA countries in the next decade, the following key priorities should be considered: (i) scaling up of evidencebased and comprehensive HIV prevention programmes targeted towards MSM; (ii) developing and scaling up migrant-sensitive prevention programmes targeted towards foreign-born nationals; and (iii) addressing the critical issue of late HIV diagnosis in the region.

\section{Acknowledgements}

We would like to thank Operational Contact Points for HIV surveillance from EU/EEA Member States participating in the European network for HIV/AIDS surveillance for their collaboration; due to their efforts and dedication, high-quality HIV/AIDS data are available in the EU/EEA: Austria: JeanPaul Klein; Belgium: Andre Sasse; Bulgaria: Tonka Varleva; Croatia: Tatjana Nemeth Blazic; Cyprus: Maria Koliou; Czech Republic: Marek Maly; Denmark: Susan Cowan; Estonia: Kristi Rüütel; Finland: Kirsi Liitsola; France: Florence Lot; Germany: Barbara Gunsenheimer-Bartmeyer; Greece: Georgios Nikolopoulos, Dimitra Paraskeva; Hungary: Mária Dudás; Iceland: Guðrún Sigmundsdóttir, Haraldur Briem; Ireland: Kate O’Donnell, Derval Igoe; Italy: Barbara Suligoi; Latvia: Šarlote Konova; Lithuania: Saulius Čaplinskas, Irma Čaplinskienè; Luxembourg: Jean-Claude Schmit; Malta: Jackie Maistre Melillo, Tanya Melillo; Netherlands: Eline Op de Coul; Norway: Hans Blystad; Poland: Magdalena Rosinska; Portugal: Helena Cortes Martins; Romania: Mariana Mardarescu; Slovakia: Peter Truska; Slovenia: Irena Klavs; Spain: Mercedes Diez Ruiz-Navarro; Sweden: Maria Axelsson; United Kingdom: Valerie Delpech. We would also like to thank Annemarie Stengaard from the WHO Regional Office for Europe and ECDC colleagues, especially Julien Beaute, Mike Catchpole, Denis Coloumbier, Caroline Daamen, Valentina Lazdina, Chantal Quinten, and Phillip Zucs.

Conflict of interest

None declared. 


\section{Authors' contributions}

AP developed the concept of the manuscript, analysed the data, wrote the first draft and responded to reviewers' comments. GS, TN and AJAG contributed to the concept of the manuscript and analysis and revised the article to ensure important intellectual content. All authors have read and approved the final manuscript.

\section{References}

1. Padian NS, McCoy SI, Karim SS, Hasen N, Kim J, Bartos M, et al. HIV prevention transformed: the new prevention research agenda. Lancet. 2011;378(9787):269-78. http://dx.doi. org/10.1016/S0140-6736(11)60877-5 PMID:21763938

2. European Centre for Disease Prevention and Control (ECDC)/ World Health Organization Regional Office for Europe. HIV/ AIDS Surveillance in Europe 2013. Stockholm: ECDC; 2014. Available from: http://www.ecdc.europa.eu/en/publications/ Publications/hiv-aids-surveillance-report-Europe-2013.pdf

3. Hamers FF, Phillips AN. Diagnosed and undiagnosed HIVinfected populations in Europe. HIV Med. 2008;9(s2) Suppl 2;6-12. http://dx.doi.org/10.1111/j.1468-1293.2008.00584.x PMID:18557863

4. Heisterkamp SH, Jager JC, Ruitenberg EJ, Van Druten JA, Downs AM. Correcting reported AIDS incidence: a statistical approach. Stat Med. 1989;8(8):963-76. http://dx.doi.org/10.1002/ sim.4780080807 PMID:2799125

5. Hedrich D, Kalamara E, Sfetcu O, Pharris A, Noor A, Wiessing $\mathrm{L}$, et al. Human immunodeficiency virus among people who inject drugs: is risk increasing in Europe? Euro Surveill. 2013;18(48):20648. PubMed PMID: 24308980

6. Antinori A, Coenen T, Costagiola D, Dedes N, Ellefson M, Gatell J, et al.; European Late Presenter Consensus Working Group. Late presentation of HIV infection: a consensus definition. HIV Med. 2011;12(1):61-4. http://dx.doi.org/10.1111/j.14681293.2010.00857.x PMID:20561080

7. Rosinska M, Janiec J, Niedzwiedzka-Stadnik M. Increase of new HIV diagnoses among men who have sex with men in Poland, 2000 to 2011. Euro Surveill. 2013;18(48):20642. PubMed PMID: 24308981.

8. Phillips AN, Cambiano V, Nakagawa F, Brown AE, Lampe F, Rodger A, et al. Increased HIV incidence in men who have sex with men despite high levels of ART-induced viral suppression: analysis of an extensively documented epidemic. PLoS ONE. 2013;8(2):e55312. http://dx.doi.org/10.1371/journal. pone.0055312 PMID:23457467

9. Ferrer L, Furegato M, Foschia JP, Folch C, Gonzalez V, Ramarli $D$, et al. Undiagnosed HIV infection in a population of MSM from six European cities: results from the Sialon project. Eur] Public Health. 2014 Aug 26. PubMed PMID: 25161202.

10. European Centre for Disease Prevention and Control (ECDC). Thematic report: Migrants. Monitoring implementation of the Dublin Declaration on Partnership to Fight HIV/AIDS in Europe and Central Asia: 2012 progress. Stockholm: ECDC; 2013. Available from: http://ecdc.europa.eu/en/publications/ Publications/dublin-declaration-monitoring-report-migrantsseptember-2013.pdf

11. Joint United Nations Programme on HIV/AIDS (UNAIDS). Global Report: UNAIDS report on the global AIDS epidemic 2013. Geneva: UNAIDS; 2013. Available from: http:// www.unaids.org/sites/default/files/en/media/unaids/ contentassets/documents/epidemiology/2013/gr2013/ UNAIDS Global Report 2013 en.pdf

12. Rice BD, Elford J, Yin Z, Delpech VC. A new method to assign country of HIV infection among heterosexuals born abroad and diagnosed with HIV. AIDS. 2012;26(15):1961-6. http://dx.doi. org/10.1097/QAD.ob013e3283578b80 PMID:22781226

13. European Centre for Disease Prevention and Control (ECDC). Migrant health: Sexual transmission of HIV within migrant groups in the EU/EEA and implications for effective interventions. Stockholm: ECDC; 2013. Available from: http:// www.ecdc.europa.eu/en/publications/Publications/Migranthealth-sexual-transmission.pdf

14. Ingle SM, May MT, Gill MJ, Mugavero MJ, Lewden C, Abgrall S, et al. Impact of risk factors for specific causes of death in the first and subsequent years of antiretroviral therapy among HIV-infected patients. Clin Infect Dis.2014 Jul 15;59(2):287-97. PubMed PMID: 24771333.

15. Oliva J, Diez M, Galindo S, Cevallos C, Izquierdo A, Cereijo J, et al. Predictors of advanced disease and late presentation in new HIV diagnoses reported to the surveillance system in Spain. Gac Sanit. 2014 Mar-Apr;28(2):116-22. PubMed PMID: 24365520.
16. Mocroft A, Lundgren JD, Sabin ML, Monforte A, Brockmeyer N, Casabona J, et al.; Collaboration of Observational HIV Epidemiological Research Europe (COHERE) study in EuroCoord. Risk factors and outcomes for late presentation for HIVpositive persons in Europe: results from the Collaboration of Observational HIV Epidemiological Research Europe Study (COHERE). PLoS Med. 2013;10(9):e1001510. http://dx.doi. org/10.1371/journal.pmed.1001510 PMID:24137103

17. Lanoy E, Mary-Krause M, Tattevin P, Perbost I, Poizot-Martin I, Dupont C, et al.; ANRS C004 French Hospital Database on HIV Clinical Epidemiological Group. Frequency, determinants and consequences of delayed access to care for HIV infection in France. Antivir Ther. 2007;12(1):89-96. PMID:17503752

18. Lazarus JV, Hoekstra M, Raben D, Delpech V, Coenen T, Lundgren JD; HIV in Europe Initiative Steering Committee. The case for indicator condition-guided HIV screening. HIV Med. 2013;14(7):445-8. http://dx.doi.org/10.1111/hiv.12022 PMID:23480600

19. European Commission. Communication from the Commission to the European Parliament, the Council, the European Economic and Social Committee and the Committee of the Regions Combating HIV/AIDS in the European Union and neighbouring countries, 2009 -2013. Brussels: European Commission; 2009. Available from: http://ec.europa.eu/health/ph_threats/com/ aids/docs/com2009_en.pdf

20. European Commission. Action Plan on HIV/AIDS in the EU and neighbouring countries: 2014-2016 Brussels: European Commission; 2014. Available from: http://ec.europa.eu/health/ sti_prevention/docs/ec_hiv_actionplan_2014_en.pdf 